\title{
A CASE OF EXCISION
}

\section{OF THE \\ HEAD $0 \mathrm{~F}$ THE HUMERUS \\ (DECAPITATIO hUMERI);}

W I TH I TS RESULTS.

\begin{abstract}
BY
JOHN BIRKETT,

SURGEON TO GUY'S HOSPITAL; FELLOW OF THE ROYAL COLLEGE OY BURGEONS OF meland, OF THE socíté de chiRuRgie of Paris, AND OF THE ROYAL MEDICAL AND CHIRURGICAL SOCIETX OF LONDON.
\end{abstract}

Received Nov. 8th.-Read Dec. 14th, 1858.

Tromas B-, æt. 57, residing at Monckton, in the Isle of Thanet, and pursuing the occupation of a bailiff, was admitted into Guy's Hospital, July 10th, 1855, under my care.

He was emaciated and cachectic; but, until after the receipt of an injury which gave rise to his present condition, he had enjoyed robust health. Two years and five months before I saw him, a cow ran against his left leg, and thrust his right shoulder, violently, against a stone wall. The right clavicle was broken, and the shoulder was much contused. Inflammation of the shoulder-joint ensued, which terminated in suppuration. Three abscesses pointed, which were opened by Mr. Freeman, the surgeon

XLII. 
of Minster, under whose care the man had been from the moment of the injury. The whole of this period was passed in great suffering, and his health had declined in consequence.

When admitted, the condition of the right upper extremity was as follows:-The arm and forearm were more or less œdematous; the least movement of the member gave him intense pain, and pus escaped from three sinuses behind, and on the outer region of the shoulder. This part was swollen, but there was not any deformity. Distinct "crepitus" was felt on moving the arm, and the head of the humerus seemed to glide away, and to be removed from its normal relations with the glenoid cavity.

Believing that it was not possible to cure the disease, which probably existed in either the head of the humerus or the glenoid cavity, or both, I suggested to the man the removal of the diseased bone, and to this proposal he readily assented.

The operation was performed on July 24th, 1855. I made a triangular flap of the integuments and deltoid muscle, with its base above, and reflected it upwards. No difficulty was experienced in reaching the head of the humerus, or in exposing it to view. Sawing off the head of the bone was also easily performed with a fine "bowsaw." A rather profuse hæmorrhage delayed the operation; the blood flowed from the posterior circumflex artery, which had not been completely divided. The man was fully under the influence of chloroform during the operation.

The articular cartilage of the head of the humerus was entirely destroyed, and, at one point, a small piece of necrosed bone was lodged in an excavation, lined with granulations, close to the articular surface. The sawn surface of the bone seemed to be quite healthy, as well as the bone forming the glenoid cavity of the scapula, the articular cartilage being destroyed. There was a large quantity of the usual vascular granulations within the capsule into which the sinuses led. After maceration, the articular osseous lamella covering the cancellous tissue of the caput 
humeri showed small foramina, just as if worm-eaten; but, in other respects, it was hard and smooth in some parts, perhaps from attrition. The focus of the disease appeared to be in the cancellous tissue situated between the great tuberosity of the shaft and the articular head; and here was an excavation, in which the piece of necrosed bone, before mentioned, was lodged. This dead piece of bone originally formed a small part of the superior and posterior circumference of the head, and the corresponding portion of the cervix of the bone. Upon it may be seen a part of the groove generally so distinctly marked in this spot.

Sutures were employed to adapt the edges of the wound, which quickly healed; nutritious food and stimuli were given freely, and the man left the hospital, August 18th, 1855, twenty-five days after the operation. At this date, the pain by which he had been tortured had ceased, his health improved immediately afterwards, and these were the first good results obtained.

October 30th, 1855. - The sinuses formed in the line of the cicatrix were not yet healed; but a thin, purulent discharge escaped from them. The general health of the patient was much improved, as well as his constitutional nutrition.

July, 1856.-A year after the operation. Pus still continued to flow from three sinuses, but, with a long probe, there was not any exposed bone to be detected. His general health was very good. Injections of the compound tincture of iodine were now used along the sinuses, and at the end of 1856 they had quite healed.

During the whole of this time the upper extremity had been well supported in a sling; but the man had used his forearm and hand, although to a limited degree.

September, 1858.- Since the end of 1856 this man has used his arm freely in the varied occupations of a farmlabourer. He can do any work which does not require a greater elevation of the arm than at a right angle with the body. The deltoid muscle has not sufficient power to raise it above the level of the acromion process of the scapula, 
nor has the upper end of the humerus obtained a sufficiently firm and fixed point upon which to move. It can be felt under the integuments, in front, near to the coracoid process of the scapula. The man enjoys perfectly good health, he is entirely free from all pain, and he is enabled to do sufficient work to obtain a livelihood.

Remarks.-I have not brought this case before the Society without duly considering whether it might not be regarded of too trifling a nature, and scarcely worthy to occupy the attention of its members. But, although "decapitatio humeri" is not very uncommonly performed, and there are records of many such operations, we have only a few cases in which the results of those operations are subsequently detailed at a distant period of time. We are, in truth, greatly in want of such recorded experience, and to this end, and in the hope of inducing others to follow the example, I offer this case for comment and observation.

The age of the patient was somewhat advanced, and this circumstance might be regarded as a cause likely to militate against the success of the operation. The man, however, had always lived in the country, had enjoyed very good health, and his habits were very steady and quite free from intemperance in any way. The cause of the disease was an injury, which would lead to the inference that a particular spot in one of the bones forming the shoulderjoint was diseased, and that the mischief in them was not extensive. From local indications, it was quite clear that diseased bone existed, and that until the cause of the local disease was removed, there could be no hope of improving or restoring the constitutional nutrition of the patient. Indeed, this case seems typical of the class of cases in which the excision of the articular ends of bones should be undertaken; for, I believe, that in all cases and in whichsoever joint, when diseased bone exists, there is very little hope of saving the limb unless that diseased bone can be speedily removed. In the majority of cases in 
which diseased bone does not exist, the cases eventually do well without an operation, and the limb is saved; it may be with a somewhat misshapen member. In the case related, a small piece of necrosed bone in the head of the humerus proved to be the source of the local irritation, which being removed, all pain and suffering immediately ceased, and the general health of the patient directly improved. Such good results as these would quite justify a repetition of the operation on patients of an advanced age, for this man was undoubtedly sinking from constitutional disturbance alone. But in progress of time a still greater advantage was obtained, for the man was quite able to follow his employment, and gain sufficient for his subsistence. The amount of elevation of the arm was certainly limited; but I am not aware that, in any case of this kind, the patient has regained the power of raising the arm above a right angle with the trunk, or above the level of the acromion scapulæ.

The following case occurred in Guy's Hospital in 1848, and affords an admirable illustration of the advantages to be gained by " decapitatio humeri :"

Excision of the Head of the Humerus, by the late Mr. Aston KeY ; from Notes taken whilst the patient was in Guy's Hospital, by Mr. Thomas Bryant, AssistantSurgeon, Guy's Hospital.

Thomas C-, an engineer, was admitted into Guy's Hospital, December 20th, 1818. He was between thirtythree and thirty-four years old.

He had always enjoyed good health until four months since, when, whilst engaged at work in Prussia, he was pulling with great force, and strained his right shoulder. Eight days afterwards he observed a swelling in the upper part of the arm, and on the inner side. This increased to ten weeks since, when it was of the size of an egg. He could move the shoulder-joint, but was unable to work. When he returned to England, he experienced so much 
pain in the shoulder that he applied to Mr. Cock, who lanced the swelling, and matter and some bodies like hydatids escaped. This afforded relief for about a week, and then acute pain was felt in the joint, which was very severe at night. Cupping over the joint diminished the pain, but after a few days had elapsed it returned, and he was admitted into Guy's Hospital.

There was considerable swelling over the right shoulder, and pain upon pressure over the same part. The joint could be moved freely, but it produced intense pain. There was a small fistulous opening in the skin, over the anterior edge of the deltoid muscle and tendon of the biceps, from which a curdy strumous secretion escaped. A probe could be passed along the sinus from this opening for about six inches towards the coracoid process.

January 30th, 1849.-Mr. Key made an incision from the coracoid process to the insertion of the deltoid muscle, and another along the posterior edge of the muscle. This flap was reflected upwards, the joint exposed, and the head of the humerus sawed off below the tuberosities. The articular surface was deprived of cartilage, and the cancellous tissue carious. The glenoid cavity of the scapula seemed to be healthy.

Profuse hæmorrhage attended the operation, and many vessels were ligatured. Sutures were used to adjust the edges of the flap to the surrounding parts, and the wound healed without an untoward circumstance.

The man left the hospital July, 1849, the wound nearly healed.

A drawing was made in February, 1856, seven years after the operation, and is in the museum at Guy's Hospital. Preparations of the head of the humerus removed in these two cases are preserved in the same museum. During the last six years the patient has been actively engaged at Messrs. Maudsley's, the engineers, and he has enjoyed excellent health. 